\title{
Concept of Climate Vulnerability: Key Determinants, Responses and Constraints to Climate Change Adaptation.
}

\author{
Isaac Sarfo \\ Department of Environment \& Development Studies, \\ Central University, Ghana. \\ Michael Boakye Yiadom \\ Department of Marketing Management, \\ Nelson Mandela University, South-Africa. \\ Jude Issa Dontoh \\ The Graduate School, \\ Ca Foscari University of Venice, Italy.
}

\begin{abstract}
The paper is essentially a synthesis report highlighting key areas of climate vulnerability as a global discourse based on reports from international conventions held over the years. Theoretically, it draws country and sector based scenarios on responses and constraints to climate adaptation. The literature is organized in phases, constituting a conceptual framework, evidence and trend of climate impacts, local ecosystem-based approach (EbA) to sustainable adaptation models, espoused across climate-sensitive sectors. The ultimate aim of this paper is to synthesize and develop a synthesis report on key determinants of climate vulnerability based on existing literature.
\end{abstract}

Keywords: Climate vulnerability; constraints; social vulnerability; social capital; Ecosystembased Approach (EbA); no-regret strategy (NRS).

\section{BACKGROUND}

\section{Climate Change: A Global Perspective}

The purpose is to enhance understanding of climate change in a global context by defining key concepts relevant to the understanding of this phenomenon. The strategy traces the origin of climate change debate starting as an international, environmental and developmental challenge beginning with a publication of Brundtland Report in 1987 through to the formation of IPCC in 1989, the 1992 United Nations Conference on Environment and Development (UNCED) in Rio de Janeiro, and the establishment of the United Nations Framework Convention on Climate Change (UNFCCC). Since then, there have been series of Conference of the Parties (COP) to the UNFCCC, which have produced 'Accords and Protocols' (i.e. Marrakesh Accords, Kyoto Protocol and the Copenhagen Accord). Key issues shaping the global climate change regime are also explained. These include mitigation, adaptation, finance, technology development and transfer, governance as well as the role of land-use and land-use change and forestry (LULUCF) in climate change mitigation especially in third-world countries.

Climate vulnerability is a concept defined by numerous scholars and international organizations. Consequently, the term vulnerability accordingly to [1] can be termed as the degree to which an individual, group or system is susceptible to harm due to exposure to a hazard or stress, and the (in)ability to cope, recover, or fundamentally adapt (become a new 
system or become extinct). In most cases vulnerability is understood as the first step that can be reduced by adaptation. It probably means most scholars and policy makers interpret adaptive capacity as ability to adapt that is not constant in time and not as a limit of adaptation. So, adaptation can enhance adaptive capacity and reduce vulnerability. According to [2], cited in [3-4], once people's vulnerability is reduced through well-focused adaptation strategies, communities and their residents will become resilient, adaptive and robust to hazards.

\section{Materials and Methods}

The paper from a qualitative perspective narrates and reviews existing theoretical concepts imbibed in several existing literature related to climate vulnerability. It reviews a number of studies, drawn from policy-frameworks, international conventions, academic and institutional research with practical case study scenarios in some countries and sectors on key determinants of climate vulnerability.

\section{Synthesis of IPCC's fifth Assessment report}

The UN's Intergovernmental Panel on Climate Change provided a refined comprehensive report on Climate Change related issues in 2014 at Copenhagen. The fifth assessment report delved into findings from several working groups in previous assessment reports which highlights the physical impacts, vulnerability and adaptive strategies. The fifth assessment report gives a holistic view on issues related to climate change across regions with several projections. IPCC's fifth assessment report highlights the following key thematic areas;

1. Age-of-Anthropocene with current global changes heavily induced by human activities with unprecedented rate of emissions of greenhouse gases (GHGs) which is creating ascendancy in global temperatures and its resultant impacts.

2. Intensification of climate change impacts such as; ocean acidification, flooding, droughts, higher temperatures, sea level rise, melting of glaciers and other climate related stress or disturbances.

3. Estimates stern efforts that ought to be put in place to regulate impacts by the end of 2100. This would avoid further increase in global temperatures above $4{ }^{\circ} \mathrm{C}$ in this industrial era where countries are expanding their economies, thus, transition of developing countries from raw material economies to well-structured (highly industrialized) economies.

4. Options to reduce emissions by adapting to green technology, including the use of low carbon energy sources such as wind, solar and nuclear. Efficient use of energy must be used.

5. Specific adaptations, adaptive capacity and resilient strategies have been institutionalized in specific societies to help cope with climate change hazards.

IPCC's comprehensive report draws attention to how prevailing climate is changing, its potential impacts, both positive and negative across regions. These changes in our environment across regions can be observed in the synthesis report;

1. Over the last century, there have been increasing of global temperatures of about $0.8^{\circ} \mathrm{C}$ with about $20 \mathrm{~cm}$ rise in sea levels.

1. In many regions, snow and rainfall patterns have changed, affecting water supply particularly freshwater in some areas in south eastern part of Asia, Africa and many others.

2. Snow, ice, permafrost and glaciers are melting at the poles and around the rest of the world.

3. The oceans are becoming increasingly acidic as they absorb more carbon dioxide.

4. Fluctuations in extreme weather events. For instance, heat waves are lasting for longer periods and becoming more intense whilst with erratic rainfall patterns. 
5. Discovery of good and new places for agriculture (Like; Siberia) and identification of new species in some areas as a result of migration and loss of some species in some areas.

6. Trees and forests have been seen to be dying off, corals are declining and bleaching, with productivity and biodiversity shift of some animals on land and in the sea from their natural habitats.

\section{Global Climate Change Projections: Expectations}

The need for global consensus and concerted efforts among international organizations, policy makers, researchers and individuals on regulating actions that significantly impact on our climate have gained tremendous weight. The assessment report made the following projections;

1. Global temperatures could be above $4{ }^{\circ} \mathrm{C}$ what they were before the industrial revolution.

2. It is very likely heat waves will occur more often and last longer, increasing the risk of health problems particularly in vulnerable populations.

3. Likelihood of heavy rainfall events and increase in its frequency in many places with resultant impacts like floods in most areas looks more likely.

4. The ocean will continue to warm and acidify, negatively affecting marine life and fisheries.

5. Global average sea level will continue to rise, disrupting communities in low-lying or flood plain areas with increasing risk of coastal flooding from storm surges.

6. Food security will be undermined as changes in the oceans affect fisheries as well as drought and rising temperatures reducing global crop yields.

7. Displacement of more people from their homes, destruction of public and personal properties.

8. Disease outbreaks and limitation of freshwater resources due to sea level rise may cause intrusion of groundwater affecting several livelihoods in prone areas.

\section{Climate Change responses}

The summary report highlights prudent strategies needed to cope or adapt to climate stress and disturbances. The report spells out the consequences of our actions, should we neglect these cautions with projections as well as how we can reduce risks associated with climate hazards should it be treated with much urgency through an integrated approach. Responses highlighted in IPCC's fifth assessment report were;

1. Substantial reductions in emission of greenhouse gases in subsequent decades will lower the risks of seeing harmful impacts later this century although we cannot reverse the situation but collective efforts can help regulate global temperatures and other climate change impacts.

2. Doubling efforts to use environmentally friendly technologies can sustain global temperature change below $2{ }^{\circ} \mathrm{C}$ by the end of the century. Global greenhouse emissions in 2050 need to be 40 to $70 \%$ lower than in 2010, and emission levels near zero or below in 2100. This means we need total human emissions of CO2 to remain less than 2900 gigatonnes of carbon-dioxide (GtCO2). We have already emitted 1900 GtCO2, which is about two thirds of this limit.

3. Need to change life styles with increasing population, use of automobiles and flights in transportation, structural changes from raw economies to industrialized economies. The longer we delay actions, the harder and more expensive it will be if we do not plan against any unforeseen event.

4. Recent extreme storms, flooding, heat-waves and droughts demonstrate our vulnerability to climate and weather events. 
5. Our options for reducing emissions include using energy more efficiently and switching to low-carbon energy sources such as renewables, nuclear energy, and fossil energy with carbon dioxide capture and storage options for reducing emissions include decarbonizing the way we produce electricity, using energy more efficiently and trying to reduce the amount of energy that we use in generating power.

6. The report provides a strengthened case for international leaders through diplomacy to act now to reduce domestic carbon emissions and to secure an ambitious legally binding global agreement.

\section{Climate Change Awareness at the Global Level}

In 2015, Institute of Green Growth Solutions (IGGS) presented a report under the auspices of MESTI, EPA, UNFCCC and UNDP on climate change learning strategies in Ghana. The report highlighted some key initiatives and background information on climate awareness programs, institutional frameworks, roles and responsibilities. The report stated that, over the past few decades, Climate Change and Environmental Education (CCEE) as well as Education for Sustainable Development (ESD) have been major tools for protecting the environment and ensuring sustainable development. Drafting these into formal and informal approach in the formulation and implementation of climate change adaptation strategies, education, training and public awareness have become pivotal to most international conventions such as the UNFCCC (Article 6 of the Convention). To meet such obligations, the National Climate Change Policy in Ghana, mentions capacity building; education, information and communication (2 out of 9) in its priority activities, as systematic pillars which must be built on in order to achieve the objectives of the policy among others [5-6]. The policy directive does not only sensitize the general public but have key elements which tries to shape the behavior and lifestyles of people on climate related issues. Behavioral change is key in enhancing climate knowledge in our quest to enhance resilience and adaptive capacity.

The report then again looked at United Nations Education, Science, and Cultural Organization (UNESCO) championing climate change education through education within the framework of the UN Decade of Education for Sustainable Development (DESD), with the objective of making climate change education a more central and visible part of the international response to climate change. This means the overall objectives of UN can be achieved through a holistic approach, thus, by tackling it using country or locally based approach. The program also targeted at helping young people appreciate the impact of global warming today with the aim of increasing "climate literacy". In achieving this, the international body aimed at strengthening the capacity of its member states to provide quality climate change education; encouraging innovative teaching approaches to integrate climate change education in schools. Raising awareness about climate change and enhancing non-formal education program through media, networking and partnerships [7]. At the Conference of Parties (CoP 20) held in Lima Peru in December 2014, emphasis were placed on the need to train teachers on climate change education and the importance of the Global Action Program on Education for Sustainable Development in advancing climate change education by developing education strategies that incorporate the issues of climate change in curricular, while also raising awareness in the designing and implementation of national development and climate change strategies. The Global Action Program required a collective approach in dealing with issues related to climate change at all levels in governance and decision-making processes.

\section{African States Climate Change Learning Action-plans}

In 2007, African heads of state adopted the African Union's Declaration on Climate Change and Development in Africa (ClimDev-Africa). The Declaration on Climate Change and Development also called on member states to ratify the Kyoto Protocol; participate in the UNFCCC; build 
capacity, and invest in data collection and early warning systems; integrate adaptation strategies into country policies; raise awareness; strengthen cooperation between national meteorological offices, hydrological centers and regional economic communities (RECS); strengthen pressure on developed countries on the 'polluter pays' principle to seek deeper greenhouse gas emission cuts. The Declaration also mandated the Africa Union (AU) Commission to follow up with the African Ministerial Conference on Environment (AMCEN), the United Nations Economic Commission for Africa (UNECA) and the African Development Bank (AfDB) $[8,5]$.

The ClimDev-Africa's ACPC capacity building program has been instituted to enhance the capacity development of African Institutions and individuals in relation to climate change policy analysis $[8,5]$. The program sought to;

- Build solid climate change knowledge based on facts and scientific evidence

- Promote climate change education, research and innovation

- Build the capacity of key stakeholders to become active participants in the response to climate change through training.

- Build the capacity of young Africans with fellowship programs by engaging university students and academics.

- Enhance climate change research capacity in African universities and research institutions by offering research grants, supporting program development and mainstreaming climate change related university curricula.

- Build capacity and increase the awareness of African policy makers such as policy makers, development practitioners, negotiators, and regional economic commissions through direct short term training, seminars and roundtables.

- Provide tailor-made climate change training programs for journalists and media professionals.

- Develop innovative programs and initiatives such as national and regional networks, communities of practice and an African panel on climate change.

- Support national panels so that knowledge generation in Africa is enhanced, and relevant platforms are developed and owned by Africans.

\section{DETERMINANTS OF CLIMATE VULNERABILITY}

Vulnerability has been categorized under three (3) main components. These components are key determinants of climate vulnerability; Climate exposure, climate sensitivity and adaptive capacity. Climate exposure is the character, magnitude, and rate of climate variation to which an area of concern is exposed. Exposure refers to the presence of people, livelihoods, environmental services and resources, infrastructure, or economic, social, or cultural assets in places that could be adversely affected by physical events and which, thereby, are subject to potential future harm, loss, or damage [9]. 
Sensitivity is the degree to which the area of concern is susceptible to a climate impact. It relates to the "degree to which a system is affected, either adversely or beneficially, by climate variability or change. The effect may be direct (e.g., a change in fish growth in response to a change in the mean, range or variability of temperature) or indirect (e.g., damages caused by an increase in the frequency of coastal flooding due to sea level rise)" [11-12, pp 254]

Adaptive capacity is the ability of the area of concern to adjust or respond to the changing conditions. It is the capability of a system to adjust to climate change including climate variability and extremes, thus, moderation of potential damages, taking advantage of opportunities, or coping with consequences [2].

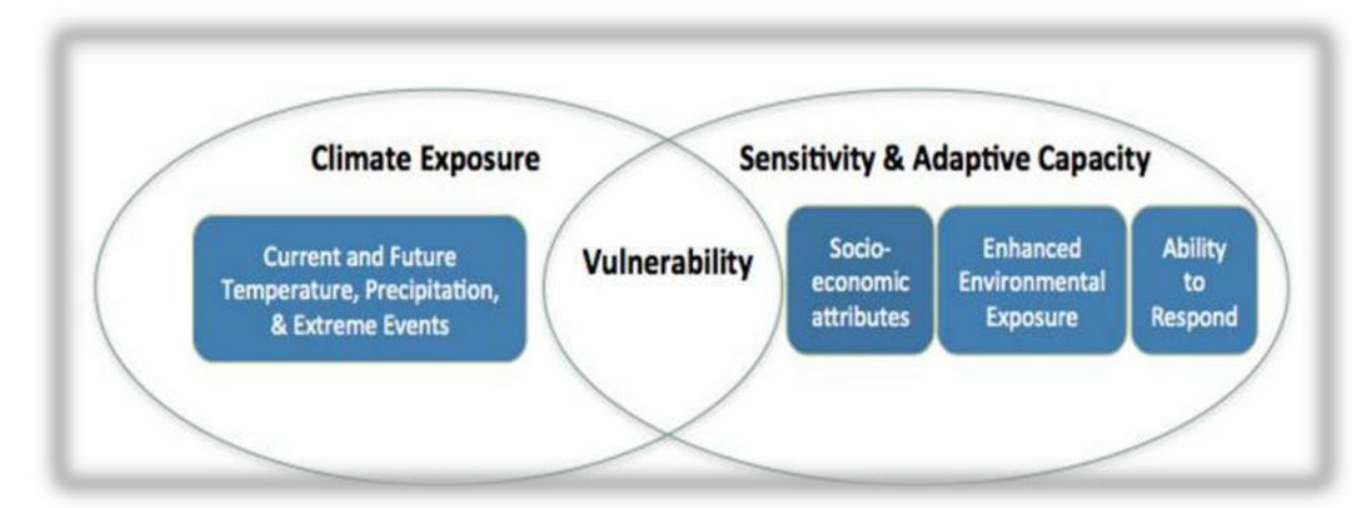

\section{Source: Petersen et al., 2014 \\ Figure 1.1: Determinants of vulnerability (Over lapse of vulnerability components)}

Figure 1.1 depicts components of climate vulnerability. [13] In his study highlighted vulnerability as a function of exposure, sensitivity and adaptive capacity.

\section{Vulnerability $(t)=F\left(\right.$ Exposure $\left._{t}\right)+\left(\right.$ Sensitivity $\left._{t}\right)-($ Adaptive Capacity $t)$}

The study shows how exposure and sensitivity have amplifying effect on vulnerability. The higher the degree of exposure and sensitivity, the higher a system's susceptibility to adverse impacts of climate change. The study further elaborated on how adaptive capacity on the other hand has a negative impact on vulnerability. Higher degree of a system's capacity to cope reduces system's degree of vulnerability to adverse impacts of climate change. These components relates to biophysical, socio-economic and environmental dimensions of climate vulnerability. This shows climate vulnerability has a multidimensional facet, thus, dynamic (changes over a period of time) and scale dependent (vulnerability can be expressed at different scales from individual through the community to country resolution; site-specific).

The encompassing nature of these components in Figure 1.1 results in aggregation of several impacts on several vulnerability dimensions, which takes into account human occupancy in a potential hazard zone, loss of lives and properties, coupled with economic assets and processes, poverty and deceasing standards of living.

\section{Climate change and coastal communities}

Coastlines around the world are home to several ecological and environmental resources. Most coastal areas are faced with erosion, gradual submersion of land and inundation. Single large scale climate events maybe further exacerbated by sea level rise or high spring tides. The IPCC Fourth Assessment Report (AR4) [14-15] identified low-lying deltas in Africa and Asia [16], semi-arid regions of Africa, south and central Asia [17-19] as particularly vulnerable to impacts of climate change. These climate change hotspots and the inhabitants in such regions have 
complex and overlapping vulnerabilities with their spatial locations, sensitivity and exposure to climate change. The study highlighted thirty-one (31) countries classified as least developed and most vulnerable to climate change. Out of these thirty-one (31) countries, twenty two (22) out of this total are from Africa with floodplains and coastlines or low-lying areas tangent to the coast thereby making them more susceptible to the impacts of climate change.

For instance, $25 \%$ of Ghana's entire population, representing a quarter of its total population live along the coast. Out of the total, about $10 \%$ depend on coastal fisheries for their livelihood. Fishery activities been the most predominant activity in the area is climate-sensitive. Hence, any adverse impacts could affect fish production as well as socio-economic livelihoods inhabitants [20]. Most countries in Africa's vulnerability to climate change is not solely the nature of their economies highly dependent on agriculture and other climate sensitive sectors like; ecotourism but high level of ignorance and cost of adaptation.

\section{Physical changes}

Several biophysical impacts of climate change have been identified in most regions around the world. The nature and extent of these impacts vary from one geographical area to another. In addressing knowledge and information gaps on biophysical impacts of climate change, [21] in a study entitled; "A review of the biophysical impacts of climate change in three hotspot regions in Africa and Asia" outlined range of biophysical impacts emanating from climate change. Among the biophysical impacts outlined were;

- Warmer oceans induced as a result of increasing global temperatures.

- Sea level rise emanating from melting of glaciers, higher temperatures causing expansion, higher and varying rainfall patterns.

- Ocean acidification resulting from decreasing $\mathrm{pH}$ levels in the ocean with more carbon being dissolved in the ocean.

- Loss of oxygen due to increasing temperatures.

- More extreme weather conditions

- Coastal erosion

- Saltwater intrusion due to sea level rise causing change in fresh groundwater after percolation (seepage).

- Increased run-off

\section{Ecosystem and bio-diversity changes}

Climate change is altering life on earth, causing widespread of species extinction, migration and behavioral changes. Fluctuations associated with climate cause plants and animals including humans to cope or adapt by either migrating or changing certain features or lifestyle to adapt in order to survive. Climate change also causes changes in timing of some biological events such as; rate of metabolism, reproduction and spawning periods, which could fundamentally transform current ecosystems and food webs. [22] In a study entitled; "Impacts of climate change on biodiversity in the coastal and marine environments of Caribbean small island developing states" highlighted range of impacts of climate change on the region's ecosystem. Among such impacts highlighted in the study were;

- Changes in habitats, diversity and productivity (Shift in diversification and productivity).

- Changes in the structure and functioning of ecosystems.

- Coral bleaching

- Changes in the size, composition and distribution of species (Pollution or formation of new hybrids).

- Spread of diseases 


\section{Socio-economic changes}

Coastal zones are key centers to enhance socio-economic and cultural development. These areas across the globe are faced with risks and hazards associated with climate change. Most coastal areas are already faced with some human activities such as; pollution, sand winning, development pressures such as; conversion of mangrove forest and swampy areas into aquaculture farms and other developmental projects. Making such areas more prone to disasters which may be further exacerbated by impacts of climate change. Most inhabitants living in coastal zones livelihood are highly dependent on climate dependent occupations like agriculture and fisheries, hence, any adverse impacts from climate change will significantly affect livelihoods of people in the area. Range of climate change impacts which may affect key socio-economic parameters in coastal areas are;

- Damage to infrastructure and human settlements

- Power outages in the energy sector particularly hydrothermal dependent economies

- Water scarcity

- Food shortage

- Displacements

- Malnutrition

- Increased mortality

- Resource conflicts due to scarcity and competition in the use of available resources

- Irrelevance of past knowledge

\section{Responses to Climate Change hazards}

Climate change strategies must be robust and dynamic, giving room for adjustments to be made in response to events. Planning should encourage robust approaches that are as insensitive as possible to the uncertainties associated with coastal climate hazards. While inaction has costs, all actions also have opportunity costs, transaction costs, and equity implications. Planning should be devolved to lower levels in governance, thereby determining actual preferences, needs and circumstances of communities.

\section{Social Vulnerability \& Social Capital Social vulnerability}

Social vulnerability can be termed as susceptibility of social groups to adverse impacts of natural stresses and disturbances, as well as their resiliency or ability to adequately recover from them [23-24]. Social dynamism of this concept is rooted in gender, social class or stratification, race, culture, nationality, age, and other power relationships [25]. It refers to "the characteristics of a person or group in terms of their capacity to anticipate, cope with, resist and recover from the impact of a natural hazard. It involves a combination of factors that determine the degree to which someone's life and livelihood are put at risk by a discrete and identifiable event in nature or in society" [26, pp 6-8].

The social vulnerability approach alone is not sufficient to plan for disasters and must be understood as part of a broader and complex approach that includes understanding geophysical hazards and innovative solutions. This means social vulnerability approach is a subset of vulnerability in a broad picture entailing; economic, environmental and technological aspects. Vulnerability assessment thus incorporates insights from the physical world but emphasizes the roles of social, economic, and political relations in the creation of hazardous situations in a specific place [27]. Vulnerability assessment examines the social distribution of risk and why some populations bear disproportionate levels of risk to disasters. Some groups in society are more prone than others to damage, loss, and suffering in the context of differing 
hazards. Key characteristics of these variations of impact include class, ethnicity, gender, disability, age, or seniority [26, pp 9].

The factors which contribute to social vulnerability highlighted by [28, pp 5] in a comprehensive study entitled: "Quantifying Social Vulnerability" delves into how social vulnerability concept can help in understanding risk to natural hazards. The study highlighted how individuals within households, communities, geographical locations and organizations are susceptible to natural hazards. Their study focused on the first level of social vulnerability, which relates to the vulnerability of an individual within a household.

\section{Levels of Social Vulnerability}

1. 1. Household/Individual entails personal attributes such as age, social class, education, gender, health and many others

2. 2. Community level $\longrightarrow$ entails relationship or interaction with those around us. Example: social capital

3. $\quad$ 3. Regional (Geographical) Level $\longrightarrow$ entails how far we are from services at various levels

4. 4. Administrative or Institutional level $\longrightarrow$ entails Disaster funding, research, technical capacity, planning, rules and regulations to regulate climate change or natural phenomenon

\section{Source: Adopted and modified from Dwyer et al., 2005 \\ Figure 1.2: Levels of social vulnerability elements, integral to understanding the risk to natural hazards.}

[29] argues that social vulnerability goes beyond destruction of public infrastructure, hence, described the concept as a set of characteristics that includes a person's initial well-being (nutritional status, physical and mental health), livelihood and resilience (assets and capitals, income and qualifications), self-protection (capability and willingness to build a safe home, use a safe site), social protection (preparedness and mitigation measures) social and political networks and institutions (social capital, institutional and environment and the likes).

[27] In their paper review on "The concept of social vulnerability: Review from Disaster Perspectives" outlined social vulnerability to emanate or significantly influenced by natural disasters which results in "poverty, exclusion, marginalization and inequities in material consumption. It is determined by physical, social, economic, and environmental factors or processes, which increase the susceptibility of a community to the impact of hazards and is conceptually located at the interaction of nature and culture that also links "socio-economic structures, cultural norms, values and environmental hazards". On the other hand, limited access to resources like; information, knowledge, technology and limited access to political power and representation are also key factors that affect social vulnerability.

\section{Concept of Social Capital}

The concept of social capital enlist features of social organizations such as social networks, social interactions, norms, social trust, and reciprocity, cooperation that facilitate coordination and cooperation, that enable people to act collectively for mutual benefits [30]. Social capital 
has three main elements namely; bonding, bridging and linking social capital. Bonding social capital is defined as the social cohesion within groups or communities. Bridging social capital refers to the structural relationships and networks cross social groupings, involving coordination or collaboration with other groups. Linking social capital crosses describe the ability of groups to engage with external agencies [31].

The concept of social capital based on several literature, is one of the most significant and effective ways of enhancing climate resilience and adaptive capacity as well as conflict management in the use of resources. Strengths embedded in social capital mechanisms as suggested by [31, pp. 22-24] encourages participation among community members and respect of local values and customs. Social capital mechanisms provides familiarity of past experience which is shared among members of a community. This concept can be more accessible due to low cost, use of local language, flexibility in scheduling. Decision-making is often based on collaboration, with consensus emerging from wide-range of discussions, often fostering local reconciliation. Social capital contributes to a process of community self-reliance and empowerment.

Per these two concepts, thus, social vulnerability and social capital highlighted above, the welfare of humans and other resources within the environment are the main focus measures, meant to enhance capacity to cope or adapt. Social vulnerability and social capital are key to understanding how people, assets or resources are at risk to climate change. The concepts help relate how key components of vulnerability can be integrated in reducing vulnerability by enhancing resilience and capacity to cope.

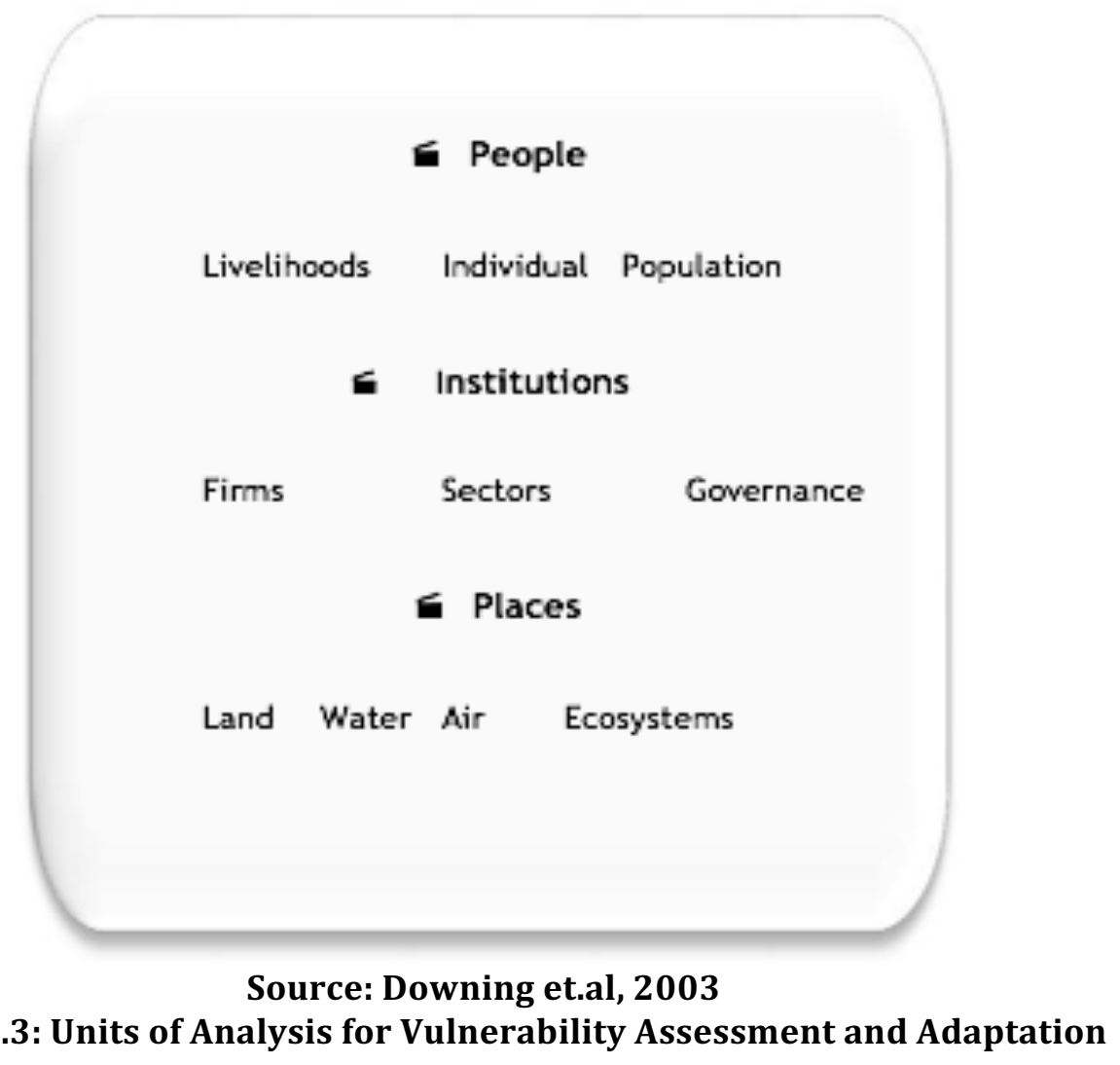

Figure 1.3 depicts units of analysis for vulnerability assessment. The key focus of vulnerability assessment is the people within the context of institutions that design, formulate, implement and evaluate the strategies in specific regions along with bio-physical resources allocated in places. These resources encounter threats posed by climate change due to human induced 
factors hence, the interrelationships that exist between these units in Figure 1.3 highlighted by [32]. The components of vulnerability assessments and adaptations are key in developing and determining effective and sustainable strategies both in the short and long run.

\section{STRATEGIES TO REDUCE CLIMATE RISKS AND VULNERABILITY}

According to [33] in a study entitled: "Climate Change Strategies", strategies can be classified under; mitigation and adaptation. Mitigation activities in reducing climate risks and vulnerability entails; reducing emission of greenhouse gases by designing and developing new alternative sources of energy, behaviors, green technologies and lifestyles that do not significantly impact on the environment. Mitigation also entails being committed in reducing rate of emissions or tackling emissions at source. Carbon sequestration (capture) through afforestation, soil processes, ocean systems and management play a fundamental role in the absorption of carbon and use of carbon for photosynthesis [11-12]. Mitigation activities are often termed as "self-protective strategies" which are costly, faster and requires a given level of technology or innovation in reducing likelihood and degree of climate change impacts.

Adaptation activities on the other hand includes; managing the change that occurs as mitigation strategies are implemented. It includes physical adaptation such as; construction of dykes, build up sedimentation, elevated sand bags, furniture and other materials as defense systems, sea wall and so on against climate events like; floods. These measures can be initiated at individual households or community levels which may be enhancing socio-economic systems which include; enhancing infrastructure, drainage systems, health and educational facilities, port construction, physical defense systems, sea defense walls or systems, resettlement or relocation schemes from flood prone areas, mangroves and so on. Adaptation is often termed as a "self-insurance strategy" which is less expensive, requires time, process and is widely used [14-15].

\section{Concept of Adaptation}

Adaptation is often linked to adverse impacts of climate change. Individuals cope by temporally relocating to live with relatives and friends when displaced by floods [34]. In terms of adaptation, some people develop defense walls, dykes, and sand bags around the water pathways or courses to prevent water from entering their homes. Adaptation is a process that involves policy driven institutions and individuals' involvement in decision-making. It was very necessary to explore individual knowledge and perception in the field to compliment concepts and findings from other researches and existing policy documents [35]. Adaptation entails anticipatory, autonomous and planned measures. Distinguished from mitigation as managing the unavoidable whilst mitigation is managing the avoidable which emanates from anthropogenic activities.

Adaptation strategies targeted towards reducing vulnerability is more sustainable [36]. [12] Defines adaptation as adjustments in ecological, social or economic systems, in response to actual or expected climatic stimuli and their effects. In line with this definition, [36] states that adaptation to the effects of climate change should incorporate response to climate hazards such as flooding and reducing extent of exposure to and building resilience against further incidence through strengthening the necessary infrastructural capacities. [37] Discussed adaptation options extensively, by delving into these areas as summarized by [35] in a study conducted on vulnerability and adaptation to flooding in Greater Accra region of Ghana:

- Use of probability models to determine vulnerability and potential damages of climate change hazards

- Using maps to show communities more affected by disasters in order to determine what strategies are best in adapting to the disasters in those areas 
- Development of early warning systems

- Awareness creation and education

- Land use planning and settlement development

- Drainage system development

[37] In the study asserted, mapping clearly the areas affected and prone to disaster, is an approach deemed more economical, realistic and action focused. The capacity to adapt varies considerably among regions, countries, and socioeconomic groups over time. The most vulnerable regions and communities are those that are highly exposed to hazardous climate change effects, and have limited adaptive capacity. Countries with limited economic resources, low levels of technology, poor information and skills, poor infrastructure, unstable or weak institutions and inequitable empowerment and access to resources have little capacity to adapt and are highly vulnerable $[38,2]$. According to $[39, \mathrm{pp} 85$ ) in a study entitled: "Institutional Challenges to Climate Adaptation in Uganda", limited technical capacity and resources limit functionality of institutions to develop effective measures, needed to reduce vulnerability in areas, prone to climate hazards. Moreover, adaptive capacity is the ability of a system to adjust to climate change, to moderate potential damage, to take advantage of opportunities, or to cope with the consequences [40]. Adaptive measures also differ based on demographic, ecological and socioeconomic characteristics of the people. [34] In a study entitled: "Improving Policy Making for Agricultural and Rural Development in Africa" noted that at the individual level, residents make prior arrangements for any natural disaster, which routinely occur every year. People resort to using blocks, stones and furniture to create higher platforms, stay with family and friends during disturbances or disaster periods among others as coping mechanisms. For instance; during floods or heavy rainstorms, neighbors adopt a number of coping strategies. Many try to draw each other's attention to the upsurge of flood, especially during heavy downpours of rain. In the process, they help each other to carry property in and out of houses before, during and after floods [41]. Some residents undertake collective work to open up drainage channels while others temporarily move to lodgings and public places such as mosques sport stadiums and churches until floodwaters recede. Some also make temporary outlets to ease floodwater movement/flow near their homes [41].

Most of these efforts are coping strategies and not sustainable adaptation options responding to the unpredictable nature of rainstorms and the potential increase in floods in recent times. Limitations to these household and community-led adaptation strategies can enhance social capital in coping with disasters but are temporal or short term measures.

\section{Traditional Knowledge: an adaptive capacity tool}

Traditional knowledge about a location and how to produce and take care of natural resources can contribute to adaptive capacity. Families have often been exposed to climate hazards in the past and have ideas on what to do to decrease their sensitivity to these hazards, and to adapt to their potential impacts [42]. These traditional ideas can lower the costs and be more culturally appropriate for villagers. In ensuring some sense of ownership, sustainability and acceptability of solutions or measures to enhance resilience, there is the need to ensure synergy between local and scientific knowledge to develop the best mechanisms with proper and consistent evaluation after implementation of adaptive measures.

\section{Ecosystem-based Approach in local climate adaptation \\ The no regret strategy concept (NRS Approach)}

In IUCN's key note address and technical paper presentation, Ecosystem based Approach (EbA) in tackling natural phenomenon was noted as the main theme. The paper highlighted key principles and core values of the "no regret strategy". The NRS concept can be termed as 
strategies, developed in response to threats posed by nature in a particular geographical area, within a given period to enhance the area's capacity to cope or adapt to any adverse impacts which may arise. The approach forms an integral part of EbA which adopts environmentally based strategies and options-through a holistic, climate risk reduction approach. The paper noted key principles embedded in this approach taking into account; stakeholder participation and consultation at various levels, promotion of synergy of indigenous and scientific knowledge at different stages of formulation and implementation process of adaptation frameworks. It reduces likelihood of maladaptation and ineffectiveness of on-going strategies by taking a holistic view into complexities of natural phenomena.

This approach is appropriate and effective in developing local adaptation strategies due to its scope of delving deep into issues, bound to occur both in the short and long term. The approach is said not to have any unintended or serious consequences after implementation (Not an obstacle to development). Evidence of success of the NRS approach are specific case scenarios in Nepal, Morocco, Uganda, Senegal, Peru and many others [43]. The NRS approach being an Ecosystem based management tool, has proven to be effective. Its effectiveness is realized by amplifying and managing time, cost-effective mechanisms, consideration and acceptance of inputs from all stakeholders during decision-making despite differing motives, views and knowledge. One major challenge of the approach is the complexity of natural phenomena which requires taking into account a range of several sectors (multidisciplinary nature of environmental problems) which maybe directly or indirectly affected by climate change impacts.

It could be concluded that, EbAs are bottom-up approaches; action based, locally-driven, robust and holistic in tackling key impacts of climate change stemming vulnerable groups based on their geographical location, social stratification and many others. With effective planning, the NRS approach has proven to reduce people's vulnerability by enhancing livelihoods through tackling key political, socio-economic and environmental factors. The next phase of this paper delves into a case scenario of the NRS approach thoroughly planned in identifying impacts of climate hazards on livelihoods, constraints and response in enhancing adaptive capacity.

\section{Case scenario: Case of Nador and Berkane in Morocco}

[44] In their study entitled; "Vulnerability and Adaption of Traditional fisheries to climate change" in Morocco, a study conducted at Nador \& Berkane between 2007 and 2010 using the no regret strategy approach to determine the socio-economic, environmental and technical capacity of the aforementioned area to cope or adapt to climate hazards. The study delved into adaptation of climate change in North-eastern part of Morocco looking at coastal adaptation to climate change impacts not just fisheries. Per the survey, fishers raised concerns in like; increased frequency of floods, change in seasonal patterns which entails wind patterns, fish spawning and crop harvest. Adaptation strategy was participatory or action based involving relevant stakeholders, whose capacity were built on impacts, need for a prudent strategy backed by concerted efforts. The Moroccan locally developed strategy in Nador and Berkane had feasible elements that tackled socio-economic, environmental and technical issues, relevant to enhancing the area's preparedness to adapt. The Moroccan NRS approach entailed nine (9) thematic areas embedded in the NRS approach classification of short and long term coastal development and climate adaptation measures. The locally designed strategy was accompanied by key measures like; implementation of coastal zone management, greater consultation and synergy of both traditional and scientific knowledge for coastal planningdevelopment with more research to inform better decision making. Strategy highlighting the nine (9) thematic areas reflects local conditions which are vulnerable or maybe placed under 
Climate change stress. The strategy meant to tackle resilience by creating livelihood alternatives for fishers, improving safety both offshore and coastal zone and improvement of fishery management \& enforcement. Also, the adaptive capacity of the strategy delved into research, creating more awareness and strengthening fishery organizations through capacity building programs on climate change and adaptation related issues whereas specific adaptations delved into flood defense mechanisms and port redevelopments. In essence, the strategy is more anticipatory and has short term remedial measures to tackle the impacts of climate change that may occur. The strategy observed caution and effective planning to mitigate impacts or reduce vulnerability in order to avoid mal-adaptation when proper and indepth planning and studies is done to formulate and implement the strategy [44]. The study called for further research in determining effectiveness of the local adaptation plan as outlined In the case of the two coastal areas in Morocco.

\section{Constraints to Adaptation}

General adaptation constraints may evolve from uncertainties about future climate and socioeconomic conditions. Other constraints may be financial, technological, institutional, social capital, and individual cognitive limits. The opportunities for planning and implementing public climate change adaptation strategies are reliant on effective strategies as well as proper mechanisms in overcoming these cleavages. The case of Nador-Berkane communities as highlighted in section 3 of this study can be largely attributed to socio-economic, institutional and biological constraints. As depicted in the figure below, effective integration of key constraints when planning holistically, can make adaptation strategies effective, thereby reducing the level of vulnerability of ecosystems in totality.

The Figure below (Figure 1.4) presents general key adaptation constraints to climate change examined by [45] in a study entitled; "Adaptation opportunities, constraints and limits to climate vulnerability and adaptation". In chapter 16 of IPCC fifth assessment report, the study highlighted key adaptation constraints that derail effective implementation of specific adaptation strategies. Hence, once adaptive capacity is not fully realized, being a component of vulnerability affects a particular group of people or sector in a particular geographical area at a given period.

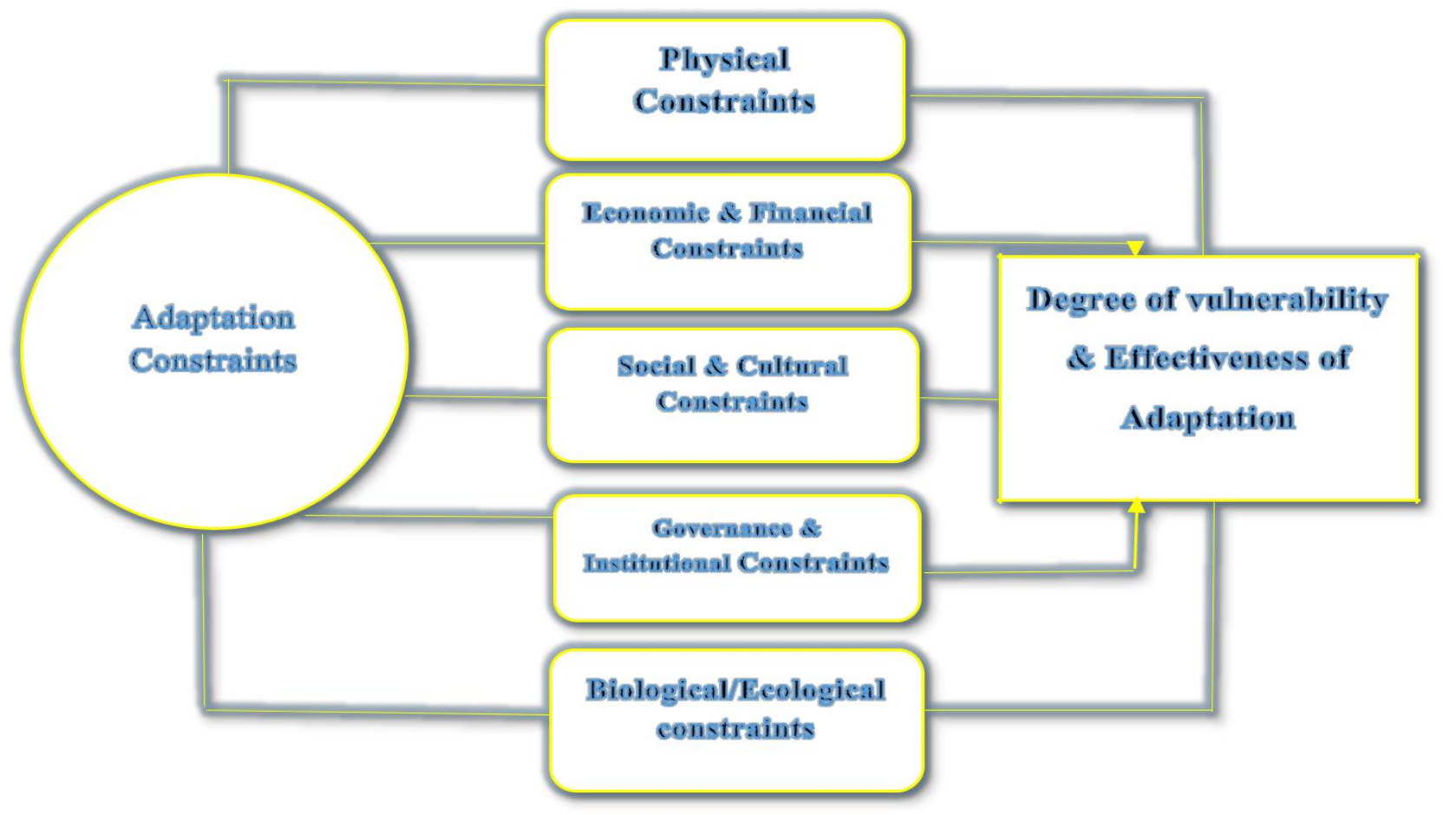

Source: Adapted and modified from Klein et al., 2014; IPCC AR5, 2014. 


\section{Physical Constraints}

Figure 1.4: Key Adaptation Constraints to Climate Change

The capacity of human population, natural systems and processes to adapt to climate change can be linked to physical environment which entails all atmospheric components. Physical constraints may be attributed to physical characteristics of some places like; coastlines and characteristics of specific geographical locations with aesthetic features. Physical capital which constitutes infrastructure and machinery to manage risks and its associated impacts in the environment [46]. Built-environment and need for continual maintenance can constrain future adaptation options and their cost of implementation.

Climate change and its associated impacts may affect groundwater systems and supply of freshwater. Enterprises or sectors that are heavily reliant on water for their day to day activities and productivity may have to cope with such changes that may affect adaptation in terms of water and food security. On the other hand, a number of studies delve into how change in water and soil quality can constrain agricultural activities as a climate-sensitive sector. The capacity of agricultural systems to adapt affects water and soil quality $[47,48]$.

\section{Economic and Financial Constraints}

Economic development and trends in globalization have significant impact on the capacity of actors to adapt to climate change [46]. Unfavorable economic conditions may influence capacity of farmers and other climate dependent occupations to cope with climate change events. Most of these farmers in developing countries are often marginalized with limited access to economic resources [38]. This in turn, increases degree of vulnerability to climate change. For instance; conversion of mangrove forest and swampy areas to shrimp farms to enhance livelihoods and for profitability is among range of economic activities that derail adaptation. Such initiatives may exacerbate the area's susceptibility to single large scale climate change event like; sea level rise [49].

Economic development poses threat on the availability, distribution of natural resources and ecosystems. A number of studies opine that, mismanagement of economic development may be an obstacle to adaptation taking into consideration the key role natural resources and ecosystems play in enhancing resilience and adaptive capacity [50]. In addition, limited access to credit facilities or financial capital such as; credits, tax revenues, insurance as well as individual household earnings may derail effective implementation of specific adaptation strategies $[51,52]$.

International aid in the form of adaptation funds and Overseas Development Assistance (ODA) channeled into adaptation programs and projects are on a decline due to lack of incentives on the part of donor agencies with concerns over ineffective utilization of previous funds or investments into adaptation programs in least developed countries. Hence; such aids when factored into planning with such uncertainty may be a constraint to adaptation [53].

\section{Social and cultural constraints}

Contemporarily, societal values, global views and cultural norms may serve as barriers to adaptation [54]. These key parameters are often linked to perceptions and beliefs in religion and culture. A number of studies on social vulnerability and environmental knowledge show negligence of traditional knowledge in some areas [55]. Case studies from several developing countries report some societal actors attribute the occurrence of natural phenomena to be driven by God and supernatural forces based on their actions and inactions. They have a firm belief that this comes in diverse ways as natural processes or as a punishment for their deeds 
at a given point. Adaptation to these natural phenomena are not amenable to human management $[56,57]$.

The perceptions and beliefs made these vulnerable groups unfazed by any challenges. Some areas have traditional ways of protecting themselves and conserving natural resourcing amid disasters. These beliefs per religion and culture to some extent, have served as an adaptive capacity tool in some areas [58]. Moreover, level of knowledge which can be attributed to level of education and availability of infrastructure, health facilities and man-made defense systems when not effective can be a constraint to adaptation which in some cases causes maladaptation to climate events.

\section{Governance and Institutional Constraints}

Institutions play a major role in facilitating adaptation through legal and regulatory responsibilities. In most developing countries, adaptation maybe constrained as a result of the complexities in governance networks or hierarchy within government and non-governmental organizations (NGOs) as well as informal community organizations such as; pressure groups or social networks [59, 60]. According to [39] in a study entitled; "Institutional Challenges to Climate Change Adaptation: A case study of policy gaps in Uganda" highlighted instances where bureaucracy, limited technical capacity, conflicting ideas of project actors and other key stakeholders affect formulation, implementation and evaluation of on-going adaptation projects were identified as key policy gaps. They opine that aforementioned factors limit effective implementation of adaptation measures needed to reduce people's vulnerability. [61] In his study asserted that, effective co-ordination among relevant stakeholders can enhance proper decision-making and implementation of adaptation strategies. Differing views, motives, objectives, level of power and resources among these actors or stakeholders may limit the achievement of common adaptation goals and objectives in reducing climate vulnerability [62, 50]. This in turn stems adaptation process and slows down effectiveness in developing appropriate measures to regulate climate stresses.

In other studies, a number of authors have highlighted how bridging the gap between informal social institutions and formal government actors through synergy can facilitate co-ordination of complex planning processes [50,63-64] by looking at the strengths and weaknesses of different governance approaches like; the top down and bottom up approaches, decentralization policy and other approaches which advocates stakeholder participation and consultation for effective planning and acceptable solutions to climate vulnerability and adaptation.

\section{Biological/Ecological Constraints}

Biological characteristics influence the capacity of organisms to cope with changing climate and its related stress in situ through acclimatization, adaptation or behavior [65] as well as diversification to suitable geographic locations to adapt. In several studies on migration and adaptation, biological capacity for migration and diversification were linked to fecundity (ability to produce off springs), genotype and phenotype variations, interspecific interactions between species and dispersal rate [66-67, 45].

Biological or ecosystem constraints on the other hand may arise from ecological degradation. This reduces availability of ecosystem goods and services, functions and endpoints, for human population. For instance; Degradation of coastal wetlands and coral reef systems may affect the capacity of buffer systems in these coastal zones to regulate strong tidal waves, tropical cyclones and other extreme weather events [68]. 


\section{Conceptual Framework}

Conceptual frameworks are used to show complex interconnections among elements that seek to outline the genesis of a phenomena and its related concepts. This paper used a framework (Figure1.5) to identify natural and human induced factors that lead to disasters associated with climate change along with resulting strategies used by nations, regions, communities and households. It provided a structure for vulnerability assessment, capacity building, management and adaptation to disasters [69, 3]. According to [41], the relevance of frameworks are their contribution in reducing vulnerabilities through strengthening resilience in communities at all levels and providing terms of reference on what to do and what to expect.

The framework indicates that disasters occur as a result of both climate and non-climate conditions. [36], [24], [4], and [14-15] further elaborated this synergy in their research findings. The non-climatic factors can be attributed to weak institutional capacity, poor in delivering mandated task due to a number of factors. Hence, do not have the capacity to develop realistic and proactive measures to manage events in the areas they operate. In tackling this global phenomenon in a holistic manner, climatic factors and non-climatic factors must be integrated as the variables highlighted in Figure 1.4 encompass each other. Limitation of most frameworks developed to enhance resilience and adaptive capacity are performance indicators in most adaptation frameworks. Performance indicators are key components in monitoring and evaluation process. This factor when sternly examined, could enhance the effectiveness of adaptation strategies, initiated by governments, communities and individual households in climate sensitive areas. 


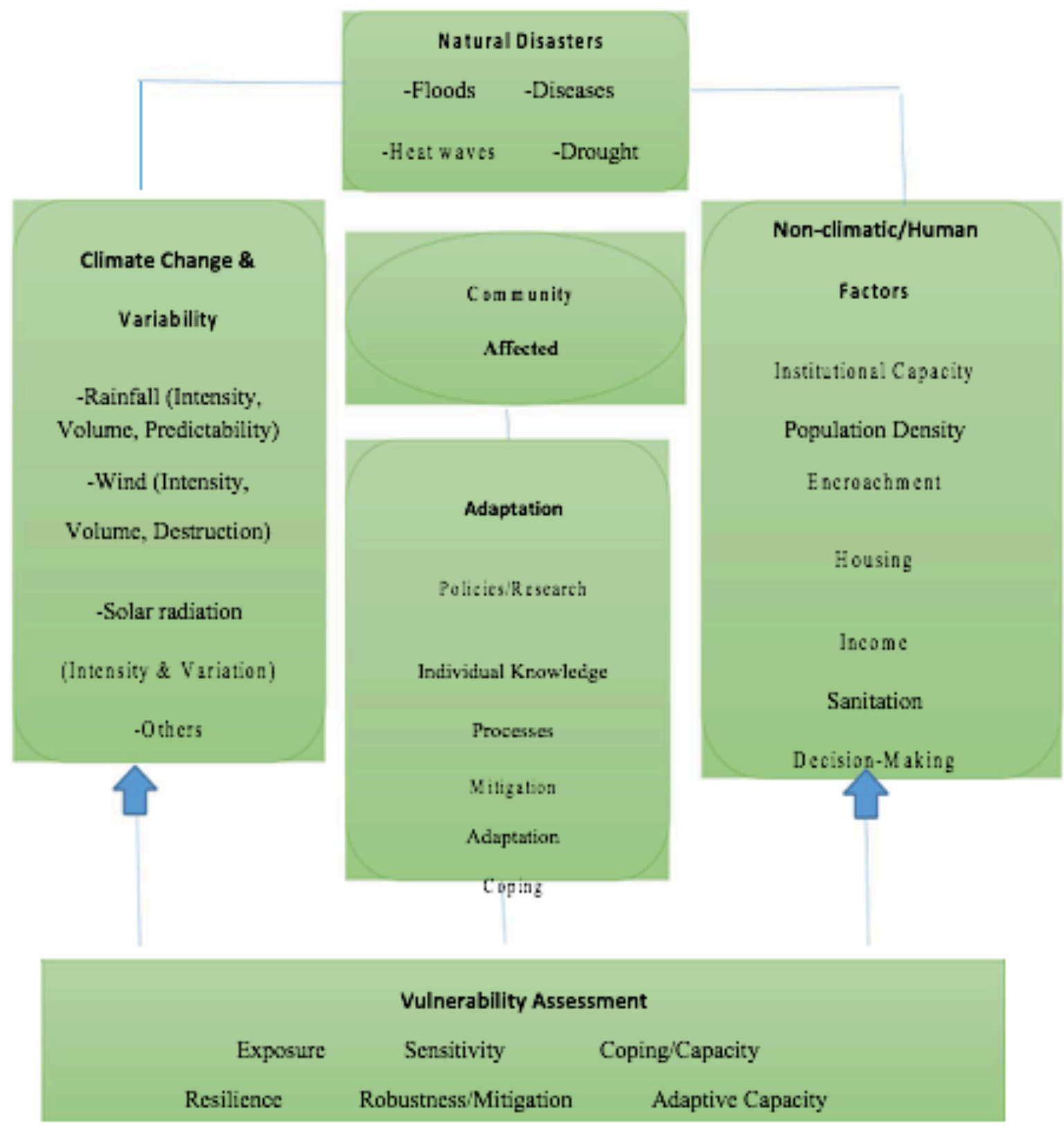

Source: Modified from Macchi, 2011.

Figure 1.5: Conceptual Framework of Vulnerability and Adaptation to Climate Change impacts.

\section{CONCLUSION}

Climate change as a global phenomenon, has gained tremendous weight over the years. The reality of this concept as a global "discourse", makes it a key subject for attention. The paper highlights a number of concepts and theories linked to climate vulnerability. In moving forward, there is the need to develop monitoring and evaluation mechanisms (performance indicators), identified as a research gap in determining how effective local, national and global adaptation strategies have been. Reducing climate vulnerability demands huge responsibility from all stakeholders backed by investments, commitments and political will. Taking a holistic and stead look at the complexity of climate issues require synergy of mainstreaming climatic and non-climatic/human factors which when derailed, reduces people and other ecosystems' capacity to adapt. 


\section{References}

Tompkins, E. et al., 2005: Surviving Climate Change in Small Islands - A Guidebook, Tyndall Center for Climate Change Research, UK

Smit, B. and Pilifosova, O. (2001). Adaptation to climate change in the context of sustainable development and equity, Climate Change 2001: impacts, adaptation and vulnerability. Contribution of Working Group II to the Third Assessment report of the Intergovernmental Panel on Climate Change, WMO/UNEP, 877-912.

Füssel, H-M (2007).Vulnerability: a generally applicable conceptual framework for climate change research. Global Environmental Change 17,155-167.

Fussel, H.M., 2009. An updated assessment of the risks from climate change based on research published since the IPCC Fourth Assessment Report. Clim. Change 97, 469-482.

Ministry of Environment, Science and Technology (2013). Africa Adaptation Program on Climate Change Ghana; Final Project Review Report, Available at:

http://www.gh.undp.org/content/dam/ghana/docs/Doc/Susdev/undp_gh_susdev_africa\%20adaptation\%20 programme\%20on\%20climate\%20change\%20ghana.pdf. Accessed on 22/7/2017.

Würtenberger, L., Bonzes, I.G, van Tilburg, X. (2011). Initiatives related to climate change in Ghana towards coordinating efforts. Netherlands: Energy Research Centre.

United Nations Development Program and United Nations Environmental Program (2010). National Climate Change Adaptation Strategy. Available at http://www.undp-

alm.org/sites/default/files/downloads/ghana_national_climate_change_adaptation_strategy_nccas.pdf. Accessed on $19 / 7 / 2017$.

African Union, 2007, Declaration on Climate Change and Development in Africa. Eighth Ordinary Session, 29-30 January 2007. (http://www.sirtewaterandenergy.org/docs/DeclarationClimateChange-AddisAbaba.pdf)

UNDP (2005). Adaptation Policy Frameworks for Climate Change. Developing Strategies, Policies and Measures, Ed.Bo Lim, Erika Spanger-Siegfried, Co-authors Ian Burton, Elizabeth Malone, Saleemul Huq.

IPCC (2001). "Africa” (Chapter 10), in Climate Change 2001: Impacts, adaptation and vulnerability. Cambridge: Cambridge University Press, 487-532.

IPCC TAR, 2001 a. Climate Change 2001: Impacts, Adaptation and Vulnerability. IPCC Third Assessment report. Cambridge University Press, Cambridge, UK.

IPCC (2001). Technical summary: climate change 2001: impacts, adaptation, and vulnerability. A Report of Working Group II of the Intergovernmental Panel on Climate Change. Retrieved from http://www.grida.no/climate/ipcc_tar/wg2/ pdf/wg2TARtechsum.pdf. (Accessed 14 ${ }^{\text {th }}$ of April, 2017).

Petersen A.C, Visser H. and Willem L. 2014. On the relation between weather related disaster impacts, vulnerability and climate change. Institute of Environmental Studies, Amsterdam, Netherland. Climate Change (2014): 125:461-477. Doi 10.1007//s10584-014-1179-z.

IPCC (2007). Climate change 2007: impacts, adaptation and vulnerability, Working Group II Contribution to the Intergovernmental Panel on Climate Change Fourth Assessment Report. Cambridge: Cambridge University Press.

IPCC (2007). Summary for Policymakers. In: Climate Change 2007: impacts, adaptation and vulnerability. Contribution of Working Group II to the Fourth Assessment Report of the Intergovernmental Panel on climate change, M.L. Parry, O.F. Canziani, J.P. Palutikof, P.J. van der Linden and C.E. Hanson, Eds. Cambridge UK: Cambridge University Press, 7-22.

Nicholls, R.J., P.P. Wong, V.R. Burkett, J.O. Codignotto, J.E. Hay, R.F. McLean, S. Ragoonaden and C.D. Woodroffe, 2007: Coastal systems and low-lying areas. Climate Change 2007: Impacts, Adaptation and Vulnerability. Contribution of Working Group II to the Fourth Assessment Report of the Intergovernmental Panel on Climate Change, M.L. Parry, O.F. Canziani, J.P. Palutikof, P.J. van der Linden and C.E. Hanson, Eds., Cambridge University Press, Cambridge, UK, 315-356.

Boko, M., I. Niang, A. Nyong, C.Vogel, A. Githeko, M. Medany, B. Osman-Elasha, R. Tabo, and P. Yanda, 2007:Africa. In: Climate Change 2007: Impacts, Adaptation and Vulnerability. Contribution of Working Group to the Fourth Assessment Report of the IPCC (Parry, M.L.; 0.F. Canziani, J.P. Van Der Linden, and C.E Hanson (eds). Cambridge University Press, Cambridge, UK and New York, NY, USA, pp 433-467.

Cruz R V, Harasawa H, Lal M, Wu S, Anokhin Y, Punsalmaa B, Honda Y, Jafari M, Li C and Huu Ninh N.2007. Asia. Climate Change 2007: Impacts, Adaptation and Vulnerability. Contribution of Working Group II to the Fourth 
Assessment Report of the Intergovernmental Panel on Climate Change, Parry M L, Canziani O F, Palutikof J P, van der Linden P J and Hanson C E (eds). Cambridge University Press. Cambridge, UK. pp. 469 - 506.

Kundzewicz, Z.W., L.J. Mata, N.W. Arnell, P. Döll, P. Kabat, B. Jiménez, K.A. Miller, T. Oki, Z. Sen and I.A. Shiklomanov, 2007: Freshwater resources and their management. Climate Change 2007: Impacts, Adaptation and Vulnerability. Contribution of Working Group II to the Fourth Assessment Report of the Intergovernmental Panel on Climate Change, M.L. Parry, O.F. Canziani, J.P. Palutikof, P.J. van der Linden and C.E. Hanson, Eds., Cambridge University Press, Cambridge, UK, 173-210.

Appeaning Addo, K. \& Adeyemi, M., 2013. Assessing the impact of sea-level rise on a vulnerable coastal community in Accra, Ghana. Jàmbá: Journal of Disaster Risk Studies 5(1), Art. Number 60, 8 pages.

http://dx.doi.org/10.4102/jamba.v5i1.60.

Kilroy G. 2015. A review of the biophysical impacts of climate change in three hotspot regions in Africa and Asia. Regional Environmental Change. June 2015, Volume 15, Issue 5, pp 771-782. doi: 10.1007/s10113-014-0709-6.

Birchenough, S.N.R. (2017) Impacts of Climate Change on Biodiversity in the Coastal and Marine Environments of Caribbean Small Island Developing States (SIDS), Caribbean Marine Climate Change Report Card: Science Review 2017, pp 40-51.

Cutter SL and Emrich CT. 2006. Moral hazards, social catastrophe: the changing face of vulnerability along the hurricane coasts. The Annals of the American Academy of Political and Social Science; 2006, 604: 102-112.

Cutter, S.L., Mitchell, J.T. and Scott, M. (2000). Revealing the vulnerability of people and places: A Case Study of George Town County South America. Annals of the Association of American Geographers, 90(4): 713-737.

Enarson E, Fothergill A, Lohri P. 2006. Gender and disaster: foundations and directions. In: Rodriguez H, Quarantelli EL, Dynes RR. (eds.). Handbook of disaster research. Springer. p. 130-146.

Blaikie P, Cannon T and Davis I. 1994 et al. At risk: natural hazards, people's vulnerability and disasters. London, UK: Routledge.

Sapam R.S, Mohammed R.E and Sarbjeet S.2014. The Concept of Social Vulnerability: A review from Disasters Perspectives. International Journal of Interdisciplinary and Multidisciplinary Studies (IJIMS), 2014, Vol 1, No.6, 71-82. 71.

Dwyer AZ, Nielsen C. and Day S. (2004). Quantifying social vulnerability: a methodology for identifying those at risk to natural hazards. Geosciences Australia Record 14; 2004.

Cannon T, Twigg J, Rowell J. Social vulnerability. 2003. Sustainable livelihoods and disasters, report to DFID conflict and humanitarian assistance department (CHAD) and sustainable livelihoods support office.

Amarasinghe 0. and Maaten B. 2011. Building Resilience: Fisheries Co-operatives in Southern Sri lanka, Springer Science business media. Doi: 10.1007/978-94-007-1582-0_17

Putnam, Robert D.: Bowling alone: America's declining social capital. Journal of Democracy Vol. 6 (1995) 1, 64-78.

Downing, T. E., \& Patwardhan, A. (2003). Assessing Vulnerability for Climate Adaptation. Adaptation Policy Frameworks for Climate Change, 69-87. https://doi.org/10.1007/978-94-007-1770-1_2

MacDonald, D. (2013). Climate Strategies 101. Earth Common Journal, Vol. 3(1). Retrieved from http://journals.macewan.ca/earthcommon/article/view/138.

Towela P.R. Nyirenda-Jere and John. Kazembe. 2014. Improving Policy Making for Agricultural and Rural Development in Africa: The vote of ICTs and knowledge management. International Institute of Environment \& Development (IIED) Working Paper, London. Retrieved from; http://pubs.iied.org/14636IIED.

Afornorpe, E. K. (2016). Flood Vulnerability and Adaptation in Accra: Examining Aspects of Both Climate and NonClimate Factors. University of Ghana Press, (March), 1-158. Retrieved from http://ugspace.ug.edu.gh

Gallopin, G.C. (2006). Linkages between vulnerability, resilience, and adaptive capacity. Elsevier Ltd.

Jha A. K., Bloch, R. and Lamond, J. (2012). Cities and Flooding a Guide to Integrated Urban Flood Risk Management for the 21st. Washington DC: The World Bank.

Sarfo I; Dontoh JI; (2018): Community-led adaptation to Climate Change among coastal communities in Ghana: The case of Dansoman in the Greater Accra region..; Advance Research Journal of Multidisciplinary Discoveries.31 (3)pp. 16-23

Ampaire E.L, Jassogne L., Happy P., Acosta M., Twyman J. , Winowiecki L, Asten P. V. (2017). “Institutional Challenges to Climate Change Adaptation: A case study on policy gaps in Uganda". Environmental Science and Policy 75 (2017) 81-90, pp 85-90. http://dx.doi.org/10.1016/j.envsci.2017.05.013 
Owaygen, M. (2010). Mapping Climate Change Vulnerability in Southeast Asia .IDRC Global Program on Climate Change and Water ESCWA.

Action Aid International (2006). Climate Change, Urban Flooding and the Rights of the Urban Poor in six African cities. Report from Action aid, Johannesburg, South Africa.

D.Mouat, J.Lancaster, I. El-Bagouri, and F. Santibanez, 2006, Eds. Opportunities for synergy among environmental conventions. Results of National and local level workshops. United Nations Conventions to Combat Desertification (UNCCD), Bonn, Germany. 52p.

Rizvi, A., Barrow, E., Zapata, F., Cordero, D., Podvin, K., Kutegeka, S., Adhikari, A. (2014). Ecosystem based Adaptation: Building on No Regret Adaptation Measures. Session of the Conference of the Parties to the UNFCCC, Session of the Conference of the Parties to the Kyoto Protocol, 11. Retrieved from www.iucn.org

Khattabi, A., \& Jobbins, G. (2011). Chapter 4: Vulnerability and adaption of traditional fisheries to climate change. International Development Research Centre, North Africa, Egypt. Eburon Delft. World Small-Scale Fisheries Contemporary Visions, 64-79.

Klein, R.J.T., G.F. Midgley, B.L. Preston, M. Alam, F.G.H. Berkhout, K. Dow, and M.R. Shaw, (2014). Adaptation opportunities, constraints, and limits in Climate Change 2014: Impacts, Adaptation, and Vulnerability. Part Global and Sectoral Aspects. Contribution of Working Group II to the Fifth Assessment Report of the Intergovernmental Panel on Climate Change [Field, C.B., V.R. Barros, D.J. Dokken, K.J. Mach, M.D. Mastrandrea,T.E. Bilir, M. Chatterjee, K.L. Ebi, Y.O. Estrada, R.C. Genova, B. Girma, E.S. Kissel, A.N. Levy, S. MacCracken, P.R. Mastrandrea, and L.L. White (eds.)]. Cambridge University Press, Cambridge, United Kingdom and New York, NY, USA, pp. 899-943.

Adger, W.N., S. Agrawala, M.M.Q. Mirza, C. Conde, K. O’Brien, J. Pulhin, R. Pulwart, B. Smit, and K. Takahashi, 2007: Assessment of adaptation practices, options, constraints and capacity. In: Climate Change 2007: Impacts, Adaptation and Vulnerability. Contribution of Working Group II to the Fourth Assessment Report of the Intergovernmental Panel on Climate Change [Parry, M.L., O.F. Canziani, J.P. Palutikof, P.J. van der Linden, and C.E. Hanson (eds.)]. Cambridge University Press, Cambridge, UK and New York, NY, USA, pp. 717-743.

Delgado, J.A., P. M. Groffman, M.A. Nearing, T. Goddard, D. Reicosky, R. Lal, and P. Salon, 2011: Conservation practices to mitigate and adapt to climate change. Journal of Soil and Water Conservation, 66(4), 118A-129A.

Olesen, J.E., M. Trnka, K.C. Kersebaum, A.O. Skjelvåg, B. Seguin, P. Peltonen-Sainio, F. Rossi, J. Kozyra, and F. Micale, 2011: Impacts and adaptation of European crop production systems to climate change. European Journal of Agronomy, 34(2), 96-112.

Agrawala, S., 2005: Putting climate change in the development mainstream: Introduction and framework. In: Bridge Over Troubled Waters: Linking Climate Change and Development [Agrawala, S. (ed.)]. Organisation for Economic Cooperation and Development (OECD), Paris, France, pp. 23-43.

Preston, B.L. 2009: Equitable climate policy in a dangerous world. In: Climate Change and Social Justice [Moss, J. (ed.)]. Melbourne University Press, Melbourne, Australia, pp. 224-245.

Herweijer, C., N. Ranger, and R.E.T. Ward, 2009: Adaptation to climate change: threats and opportunities for the insurance industry. The Geneva Papers, 34, 360-380.

Islam, M., S. Sallu, K. Hubacek, and J. Paavola, 2014: Limits and barriers to adaptation to climate variability and change in Bangladeshi coastal fishing communities. Marine Policy, 43, 208-216

Buob, S. and G. Stephan, 2013: On the incentive compatibility of funding adaptation.Climate Change Economics, 04(2), 1350005, doi: 10.1142/S201000781350005X

Hartzell-Nichols, L., 2011: Responsibility for meeting the costs of adaptation. Wiley Interdisciplinary Reviews: Climate Change, 2(5), 687-700.

Pearce, T., H. Wright, R. Notaina, A. Kudlak, B. Smit, J. Ford, and C. Furgal, 2011:Transmission of environmental knowledge and land skills among Inuit men in Ulukhaktok, Northwest Territories, Canada. Human Ecology, 39(3), 271-288.

Artur, L. and D. Hilhorst, 2012: Everyday realities of climate change adaptation in Mozambique. Global Environmental Change, 22(2), 529-536.

Kuruppu, N. and D. Liverman, 2011: Mental preparation for climate adaptation: The role of cognition and culture in enhancing adaptive capacity of water management in Kirabati. Global Environmental Change, 21(2), 657-669.

Brunsma, D.L., D. Overfelt, and J.S. Picou, 2010: The Sociology of Katrina: Perspectives on a Modern Catastrophe. Brown and Littlefield, Lanham, MD, USA, 365 pp. 
Rosenau, J.N., 2005: Strong demand, huge supply: governance in an emerging epoch. In: Multi-level Governance [Bache, I. and M. Flinders (eds.)]. Oxford University Press, Oxford, UK, pp. 31-48.

Sosa-Rodriguez, F.S., 2013: From federal to city mitigation and adaptation: climate change policy in Mexico City. Mitigation and Adaptation Strategies for Global Change, doi: 10.1007/s11027-013-9455-1.

Grothmann, T., 2011: Governance recommendations for adaptation in European urban regions: results from five case studies and a European expert survey. In: Resilient Cities: Cities and Adaptation to Climate Change [OttoZimmermann, K. (ed.)]. Springer, Dordrecht, Netherlands, pp. 167-176.

Zinn, M.D., 2007: Adapting to climate change: environmental law in a warmer world. Ecology Law Quarterly, 34(1), 61-105.

National Research Council, 2010: Adapting to the Impacts of Climate Change. America's Climate Choices: Panel on Adapting to Impacts of Climate Change, Division on Earth and Life Studies, National Research Council, The National Academies Press, Washington, DC, USA, 272 pp.

UKCIP, 2011: Making Progress: UKCIP \& Adaptation in the UK. UK Climate Impacts Programme (UKCIP), Oxford, UK, 99 pp.

Somero, G.N., 2010: The physiology of climate change: how potentials for acclimatization and genetic adaptation will determine 'winners' and 'losers'. The Journal of Experimental Biology, 213(6), 912-920.

Aitken, S.N., S. Yeaman, J.A. Holliday, T. Wang, and S. Curtis-McLane, 2008: Adaptation, migration or extirpation: climate change outcomes for tree populations. Evolutionary Applications, 1(1), 95-111.

Hellmann, J.J., K.M. Prior, and S.L. Pelini, 2012: The influence of species interactions on geographic range change under climate change. Annals of the New York Academy of Sciences, 1249(1), 18-28.

Gedan, K.B., M.L. Kirwan, E. Wolanski, E.B. Barbier, and B.R. Silliman, 2011: The present and future role of coastal wetland vegetation in protecting shorelines: answering recent challenges to the paradigm. Climatic Change, 106, 7-29.

Macchi, M. (2011). Framework for community-based climate vulnerability and capacity assessment in mountain areas. Kathmandu: ICIMOD. 